\title{
Filler-Induced Structural Order and Mechanical Properties of Polystyrene-Silica Nanocomposites
}

\author{
Yoshikazu KONDO ${ }^{* 1}$, Keisuke SOMEYA ${ }^{* 2}$, Nobumitsu YAMADA ${ }^{* 2}$, and Tsuyoshi KIJIMA ${ }^{* 2}$ \\ ${ }^{* 1}$ Advanced Materials Research Lab. KRI Inc., Kyoto 600-8813, Japan \\ ${ }^{* 2}$ Department of Functional Materials Science, Materials Science and Energy Engineering, \\ Graduate School of Engineering, Miyazaki University, Miyazaki 889-2192, Japan \\ (Received : June 23, 2005)
}

\begin{abstract}
This study is concerned with the relationship between wide angle X-ray scattering (WAXS) analysis and physical properties of amorphous polystyrene ( $\mathrm{PS})$-silica $\left(\mathrm{SiO}_{2}\right)$ composites. Nanoporous $\mathrm{SiO}_{2}$ for the fillers was prepared by the hydrothermal reaction and the structures of the composites were examined by WAXS. In their WAXS patterns, two characteristic peaks, inner peak and outer peak, were observed at $q \doteqdot 7 \mathrm{~nm}^{-1}$ and $15 \mathrm{~nm}^{-1}$ corresponding to the intermolecular structure of PS chains and the intramolecular order of benzene rings, respectively. The ratio $\left(I_{i n} A_{\text {out }}=P\right)$ in intensity of the inner peak $\left(I_{\text {in }}\right)$ to outer peak $\left(I_{\text {out }}\right)$ affords the structural parameter to well characterize the intermolecular and intramolecular structures of PS molecules and the $P$ values are observed to change widely from 0.183 to 1.16 depending on the material compositions. The elongation at the break point increases monotonously with increasing $P$, whereas the yield strength and the Young's modulus decrease with $P$ for $P=0.497$ or below but remain almost constant for larger $P$ values. The elongation of $4.5 \%$ for (PS+MPS) $/ \mathrm{SiO}_{2}$ is enormously larger than those for PS and the other composites, in contrast to a slight decrease of the other two properties relative to those for PS. It is also revealed that a strong interaction works between the $\mathrm{COO}$ or $\mathrm{COOH}$ groups of maleic anhydride modified polystyrene (MPS) and the $\mathrm{OH}$ groups of $\mathrm{SiO}_{2}$, which makes the PS polymer molecules to stack regularly on $\mathrm{SiO}_{2}$ nanofillers, leading to control the physical properties of the composites.
\end{abstract}

Key Words: PS / MPS / $\mathrm{SiO}_{2}$ / Nanocomposite / WAXS / Inner peak / Outer peak

\section{INTRODUCTION}

Polystyrene (PS) is one of the most widely used plastics with many excellent properties such as transparency, formability, rigidity for packages, sheets or films, molding, foaming and so on. However, PS is very brittle due to its high $T_{\mathrm{g}}$ and amorphous structure. For improving these poor properties, high impact polystyrene (HIPS) or polyacrylonitrilepolystyrene copolymer with butadiene particles (ABS,AS,etc) has been developed, however the lack of transparency is largely disadvantages for many applications.

Recently, increasing attention has been focused on the highly functional materials based on nanometer-sized building units such as nanoparticles and nanotubes. ${ }^{1)}$ A variety of layered, hexagonal or cubic nanostructured inorganic solids templated by surfactant assemblies and their deorganized or ion-exchanged porous ones have been extensively synthesized to provide a fundamental class of materials for nanotechnological devises and systems. ${ }^{2,3)}$ One of the most important applications of nanomaterials is directed to the fillerreinforced polymer composites. Clay minerals have been applied for the polymer composites in which the delaminated silicate plates as a reinforcing material are uniformly dispersed in a matrix of nylon $6{ }^{4)}$ polypropyrene ${ }^{5}$ or other engineering polymers. These polymer/clay nanocomposites are classified into a new family of engineering plastics in respect of their higher strength, higher modulus, higher heat distortion temperature, and lower gas permeability. ${ }^{\text {) }}$

In previous studies about WAXS observation of PS ${ }^{7-11)}$, it was shown that the two characteristic peaks were observed at $q=7.5 \mathrm{~nm}^{-1}$ (inner peak) and $10.0 \mathrm{~nm}^{-1}$ (outer peak) corresponding to the intermolecular distances of PS chains and benzene rings interaction, respectively. The intensity of inner peak was increased by drawing or heating, whereas the intensity of outer peak was a little changed and therefore the ratio $\left(=I_{\text {in }} / I_{\text {out }}\right)$ in intensity of inner to outer peak was correlated primarily with the intermolecular structure of PS. According to these reasons the inner peak was named as "polymer peak". In this study, the nanocomposites composed of nanoporous $\mathrm{SiO}_{2}$ and PS or PS/MPS (maleic anhydride modified PS) were prepared to examine their structures by WAXS method and it 
was first revealed that the characteristic WAXS patterns are strongly related to the physical properties of these composites.

\section{EXPERIMENTAL}

\subsection{Preparation of Mesostructured Silica}

Two kinds of hexagonal mesoporous silica were synthesized by the templating method using cationic surfactant in a manner of Kresge et al. ${ }^{12)}$ Fused silica, cetyltrimethyl ammonium chloride (CTAC), $\mathrm{NaOH}$, and $\mathrm{H}_{2} \mathrm{O}$ were mixed at a molar ratio of $1 / 0.45 / 0.25 / 67$, and then reacted at $140{ }^{\circ} \mathrm{C}$ for 48 hours under the hydrothermal condition. The resulting precipitate was washed with pure water three times and then dried in air oven to yield CTAC-complexed hexagonal mesophase silica $\left(\mathrm{SiO}_{2}(\mathrm{St})\right)$, followed by the calcination at $500^{\circ} \mathrm{C}$ for 7 hours to obtain hexagonal-structured mesoporous silica $\left(\mathrm{SiO}_{2}\right)$.

\subsection{Preparation of Polymer-Nanofiller Composite Films}

Atactic-polystyrene (PS;US310) from Idemitsu Petro Chemical, and modified polystyrene with maleic anhydride of $12.5 \mathrm{~mol} \%$ (MPS) from Sigma-Aldrich Japan for introducing the polar group to PS were used for preparing the composite materials. PS and a 95:5 (wt/wt) mixture of PS and MPS for the matrix polymers were dissolved in toluene in the polymer mixtures. The latter will be abbreviated as PS+MPS. The silica/polymer nanocomposites were prepared as follows. A given amount of $\mathrm{SiO}_{2}(\mathrm{St})$ or $\mathrm{SiO}_{2}$ was ultrasonically dispersed in toluene and then each dispersion was mixed with PS or (PS+MPS) at a polymer concentration of $20 \mathrm{wt} \%$ in each solution. Filler dispersed polymer solution was apparently transparent due to the perfect dispersion of nanofillers in polymer solution and casted on a glass plate and then the solvent was evaporated to form a transparent thin film of $200 \mu \mathrm{m}$ thick.

\subsection{Characterization of Fillers and Nanocomposites}

The nanofillers and obtained composite films were characterized by the following analytical methods. XRD measurements were conducted on a Shimadzu XD-D1 diffractometer with $\mathrm{Cu} \mathrm{K} \alpha$ radiation at a scanning rate of 2 degree/min. Scanning electron microscopic (SEM) images were observed by a Hitachi H-4100M. Energy dispersive Xray (EDX) microanalysis was carried out on a HORIBA EMAX-5770. Thermogravimetric and differential thermal analyses (TG/DTA) were observed by a SEIKO TG/ DTA320U with a heating rate of $10{ }^{\circ} \mathrm{C} / \mathrm{min}$ in air. Fourier transform infrared (FT-IR) spectra were measured by the $\mathrm{KBr}$ pellet method using a Nippon Bunko FT/IR-300. The film was cut into specimens $5 \mathrm{~mm}$ wide and $30 \mathrm{~mm}$ long for the tensile test. The physical properties are obtained by the methods of JIS K-7113.

\section{RESULTS}

\subsection{Characterization of Fillers}

The silica fillers, $\mathrm{SiO}_{2}$ and $\mathrm{SiO}_{2}(\mathrm{St})$, used here were primarily examined by X-ray diffraction to characterize their hexagonal structures. The BET measurement of $\mathrm{SiO}_{2}$ gave a very large value of $1.18 \times 10^{3} \mathrm{~m}^{2} / \mathrm{g}$ for the specific surface area and $3 \mathrm{~nm}$ for the pore diameter, as shown in Fig. 1. The particle sizes of $\mathrm{SiO}_{2}$ and $\mathrm{SiO}_{2}(\mathrm{St})$ were less than $100 \mathrm{~nm}$ by SEM observation (Fig. 2).

\subsection{WAXS Analysis of PS- and (PS+MPS)-Nanofiller Composites}

According to a structure model for PS proposed by Mitchell and Windle, ${ }^{11)}$ the structure of PS is separated essentially into the intermolecular structure (named 'superchain') and the intramolecular or intermolecular stacking of benzene rings, as schematically shown in Fig. $3 .{ }^{13)}$ The former (long range structures) and the latter (short range structures) can be correlated to two characteristic peaks typically observed at around $q=7 \mathrm{~nm}^{-1}$ (inner peak) and $15 \mathrm{~nm}^{-1}$ (outer peak), respectively, in the WAXS pattern of PS. Each peak is characterized in detail by three parameters, the scattering

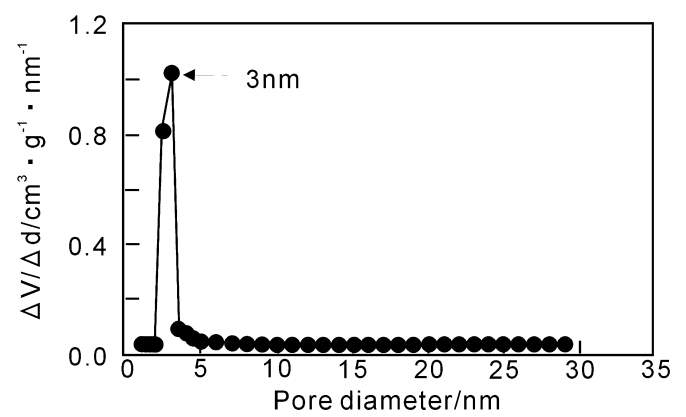

Fig. 1. Pore size distribution curve for $\mathrm{SiO}_{2}$ nanofiller.
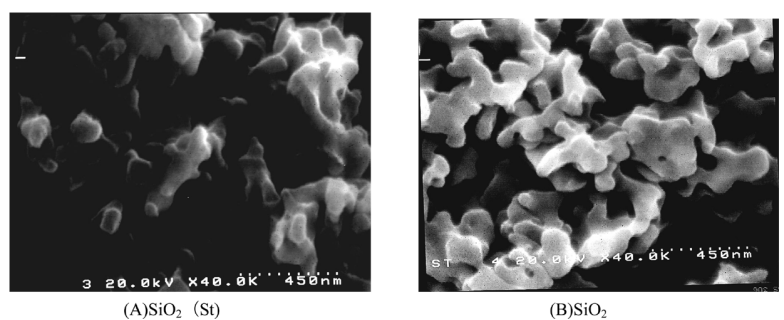

Fig. 2. SEM images of the $\mathrm{SiO}_{2}$ and $\mathrm{SiO}_{2}(\mathrm{St})$ nanofillers used. 
vector $(=q)$ defined as the following Eq.(1), scattering intensity $(=I)$ and half width $\left(=H_{I / 2}\right) \cdot{ }^{14)}$ Here, the $q$-value means the first order approximation of the intermolecular distance of PS or intramolecular distance of benzene rings, $I$ the probability of the molecules with same $q$, and $H_{1 / 2}$ the dispersion of intermolecular distance of PS or the intramolecular distance of benzene rings. ${ }^{15)}$

$$
q=4 \pi / \lambda \sin (2 \theta / 2)
$$

These parameters were evaluated from the WAXS patterns of the present composites systems shown in Fig. 4. From the results of evaluations summarized in Table I, II and Figs. 5 and 6 we can see quite opposite tendencies in WAXS parameters between the PS and the PS+MPS based composites. For the

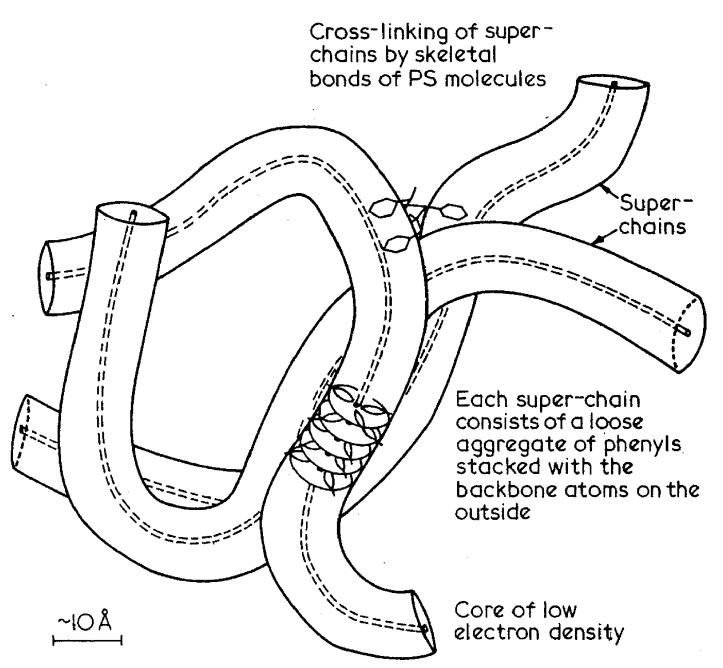

The essential features of the superchain model

Fig. 3 PS intermolecular and intramolecular structure proposed by Michell et al. ${ }^{13)}$
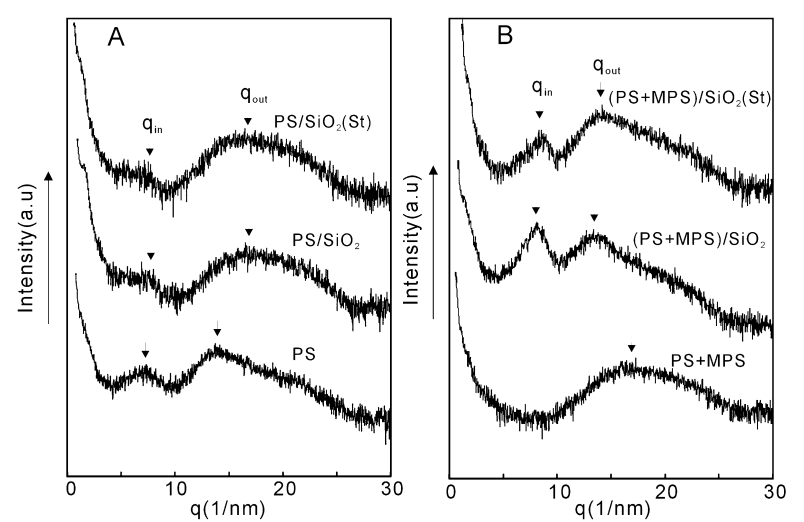

Fig. 4 WAXS charts of matrix polymers and their composites with silica fillers for the (A) PS and (B) PS+MPS systems. The inner and outer peaks are indicated by arrows.
Table I WAXS parameters of polymers and their nanocomposites.

\begin{tabular}{|c|c|c|c|c|c|c|}
\hline \multirow[b]{2}{*}{ polymer/filler } & \multicolumn{3}{|c|}{ Inner halo } & \multicolumn{3}{|c|}{ Outer halo } \\
\hline & $\begin{array}{l}q_{\text {in }} \\
(/ \mathrm{nm})\end{array}$ & $\begin{array}{l}1 \text { in } \\
\text { a.u. }\end{array}$ & $\begin{array}{c}\mathrm{H}_{1 / 2 \text { in }} \\
\mathrm{rad} .\end{array}$ & $\begin{array}{l}\text { qout } \\
(/ \mathrm{nm})\end{array}$ & $\begin{array}{l}\text { I out } \\
\text { a.u. }\end{array}$ & $\begin{array}{c}\mathrm{H}_{1 / 2 \text { out }} \\
\text { rad. }\end{array}$ \\
\hline PS/- & 7.2 & 60 & 0.071 & 13.7 & 160 & 0.123 \\
\hline $\mathrm{PS} / \mathrm{SiO}_{2}$ & 7.11 & 31 & 0.038 & 16.8 & 87 & 0.195 \\
\hline $\mathrm{PS} / \mathrm{SiO}_{2}(\mathrm{St})$ & 6.65 & 29 & 0.041 & 16.3 & 99 & 0.174 \\
\hline$(P S+M P S) /-$ & $(6.96)^{a)}$ & $(19)^{\mathrm{a})}$ & $(0.017)^{a)}$ & 15.3 & 104 & 0.183 \\
\hline$(\mathrm{PS}+\mathrm{MPS}) / \mathrm{SiO}_{2}$ & 8.07 & 246 & 0.071 & 13.6 & 212 & 0.127 \\
\hline$(\mathrm{PS}+\mathrm{MPS}) / \mathrm{SiO}_{2}(\mathrm{St})$ & 8.01 & 83 & 0.057 & 13.1 & 167 & 0.118 \\
\hline $\begin{array}{l}\text { The } q \text { is scattering vecto } \\
\text { half wide of XRD peak. } \\
\qquad \mathrm{q}(/ \mathrm{nm})=4 \pi / \lambda \times \sin \theta\end{array}$ & or and defin & as follo & geq., and & d $H_{1 / 2} \mathrm{~m}$ & & ty and the \\
\hline
\end{tabular}

Table II Parameter $P$ and physical properties of polymers and the composites.

\begin{tabular}{lcccc}
\hline \multicolumn{1}{c}{ polymer/filler } & $P\left(=\right.$ lin $\left._{\text {in }} / \mathrm{l}_{\text {out }}\right)$ & $\mathrm{S}(\mathrm{MPa})$ & $\mathrm{E}(\mathrm{GPa})$ & $\varepsilon(\%)$ \\
\hline $\mathrm{PS} /-$ & 0.375 & 1.43 & 1.47 & 3.13 \\
$\mathrm{PS} / \mathrm{SiO}_{2}$ & 0.356 & 2.11 & 1.15 & 2.75 \\
$\mathrm{PS} / \mathrm{SiO}_{2}$ (St) & 0.293 & 1.76 & 1.44 & 2.15 \\
$(\mathrm{PS}+\mathrm{MPS}) /-$ & 0.183 & 2.55 & 1.54 & 2.51 \\
$(\mathrm{PS}+\mathrm{MPS}) / \mathrm{SiO}_{2}$ & 1.16 & 1.35 & 0.55 & 4.5 \\
$(\mathrm{PS}+\mathrm{MPS}) / \mathrm{SiO}_{2}(\mathrm{St})$ & 0.497 & 1.18 & 0.72 & 2.63 \\
\hline
\end{tabular}

$\mathrm{S}$,yield strength; E, initial modulus; $\varepsilon$, elongation at break point.

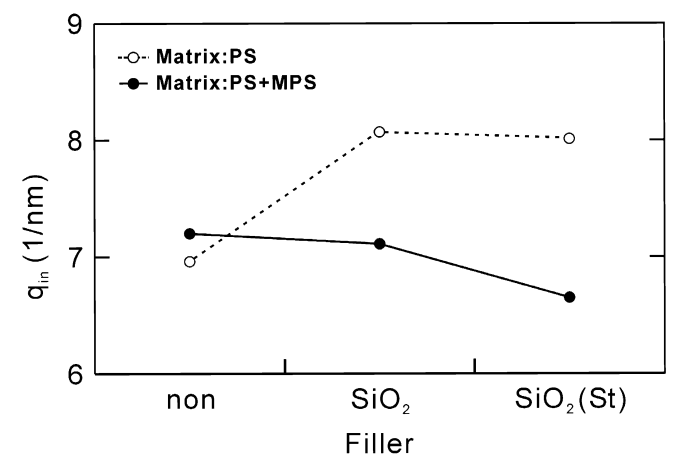

Fig. 5 Relationship between scattering vectors $q_{\text {in }}$ inner peak for polymers and the compositions of the composites. Non means polymer only and $\mathrm{SiO}_{2}$ and $\mathrm{SiO}_{2}(\mathrm{St})$ show the fillers used in composites.

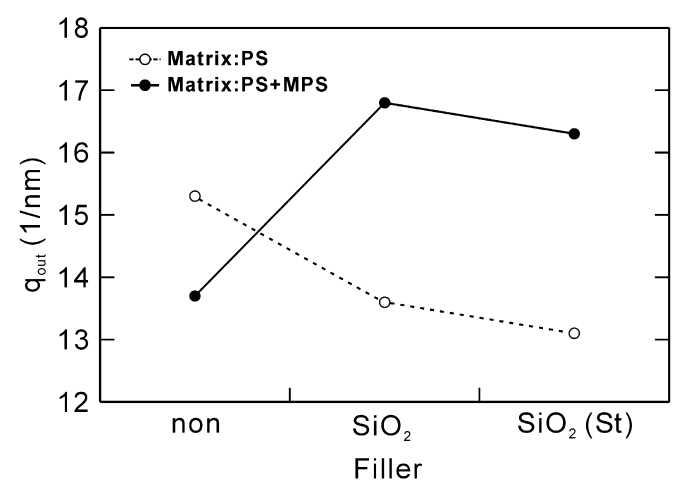

Fig. 6 Relationship between scattering vectors $q_{\text {out }}$ of outer peak for polymers and the compositions of the composites. Non means polymer only and $\mathrm{SiO}_{2}$ and $\mathrm{SiO}_{2}(\mathrm{St})$ show the fillers used in composites. 
the outer peaks are smaller and broader than those for PS matrix. In more detail, the $q_{\text {in }}, I_{\text {in }}$ and $I_{\text {out }}$ values for these composites are smaller than those for PS alone, whereas the $q_{\text {out }}$ and $H_{\text {out }}$ values for the formers are larger than those for PS alone. These findings indicate that on mixing with $\mathrm{SiO}_{2}$ or $\mathrm{SiO}_{2}(\mathrm{St})$ fillers the intermolecular distances of PS molecules become larger and the intermolecular polymer structures become less regular. This means that there is no strong interaction between PS molecules and fillers in the $\mathrm{PS} / \mathrm{SiO}_{2}$ and $\mathrm{PS} / \mathrm{SiO}_{2}(\mathrm{St})$ composites, which leads to an increase of the intermolecular distances of PS because the fillers are independently dispersed among the polymer chains. For the (PS+MPS) $/ \mathrm{SiO}_{2}$ and (PS+MPS) $/ \mathrm{SiO}_{2}(\mathrm{St})$ composites, on the other hand, it is observed that the inner and the outer peaks are larger and narrower than those of (PS+MPS) matrix. The $q_{\text {in }}$, $I_{\text {in }}$ and $I_{\text {out }}$ values for both composites are much larger than those for (PS+MPS) matrix, whereas $q_{\text {out }}, H_{\text {in }}$ and $H_{\text {out }}$ values for the formers are smaller than those for the latter. These observations indicate that both the $\mathrm{SiO}_{2}$ and $\mathrm{SiO}_{2}(\mathrm{St})$ fillers mixed with PS+MPS matrix act to decrease the intermolecular distances of polymer chains and increase the regularity of the intermolecular polymer structures, in marked contrast to the MPS-free systems.

For further discussion about the structural properties of the present materials, we introduce the parameter $P$ defined as Eq.(2).

$$
P=I_{\text {in }} / I_{\text {out }}
$$

For example, it is known that the intensity of inner peak $\left(=I_{i n}\right)$ for PS films is significantly increased by drawing or annealing, but the intensity of outer peak $\left(=I_{\text {out }}\right)$ is decreased or little affected by these treatment, according to the changes of intermolecular and intramolecular structures of PS ${ }^{11)}$. Thus the parameter $P$ can be taken as an effective measure to evaluate primarily the degree of order or disorder of the intermolecular in PS-based systems.

In the filler-free systems, the $P$ value for (PS+MPS) is decreased to 0.183 relative to the $P$ value of 0.37 for PS, because the bulky maleic anhydride groups in MPS would disturb PS intermolecular structure and increase the average distances between of PS molecules. In marked contrast, the $P$ values for the (PS+MPS) $/ \mathrm{SiO}_{2}$ and (PS+MPS) $/ \mathrm{SiO}_{2}(\mathrm{St})$ composites systems are largely increased to 1.160 and 0.497 much more than those for PS or (PS+MPS) matrix, respectively. This is because the numbers of PS molecules assembled at same $q$ values are distinctly increased through the strong interaction between $\mathrm{COO}$ - or $\mathrm{COOH}$ groups of
MPS in the matrix polymer and $\mathrm{OH}$ groups on the surface of $\mathrm{SiO}_{2}$ or $\mathrm{SiO}_{2}(\mathrm{St})$, although the overall fraction of the maleic anhydride modified polymer (MPS) in the matrix polymer is as small as $5 \mathrm{wt} \%$.

In the previous study ${ }^{11)}$, a definite increase in intensity of inner peak was observed for drawing or heating PS film, but the $P$ values remained at $0.4-0.5$ or below. Therefore it is worth remarking that the marvelously large $P$ values more than 1.0 is observed in the present study. It is also remarked that the $P$ values for the $\mathrm{SiO}_{2}(\mathrm{St})$ composites are much less than those for the $\mathrm{SiO}_{2}$ ones. This is because the external and the cylindrical internal surface of $\mathrm{SiO}_{2}(\mathrm{St})$ particles are mostly covered with the surfactant molecules, leading to a significant decrease in direct interfacial interaction between matrix polymer molecules and silica particle surface.

On the basis of the above observations, we can propose the formation mechanism of the present composites based on the interaction between polymer and fillers, as schematically shown in Fig. 7. In the (PS+MPS) $/ \mathrm{SiO}_{2}$ composites with large $P$ values, polymer molecules are attracted to the surfaces of $\mathrm{SiO}_{2}$ nanofillers through the hydrogen bond or electrostatic interaction, which induces epitaxial assembling of polymer chains on $\mathrm{SiO}_{2}$. Usuki also reported a similar finding that a stacking structure of several layers of SEBS polymer molecules formed on the surface of fillers in $\mathrm{SEBS} / \mathrm{SiO}_{2}$ nanocomposite was observed by TEM method. ${ }^{16)}$

In short, the present data reveal that the strong interaction between $\mathrm{COO}$ - or $\mathrm{COOH}$ groups of MPS and surface $\mathrm{OH}$ groups of $\mathrm{SiO}_{2}$ or $\mathrm{SiO}_{2}(\mathrm{St})$ in the mixed polymer composites
PS
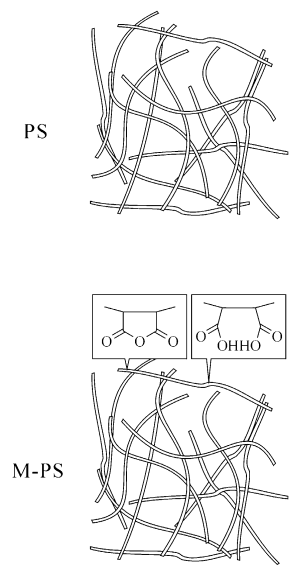
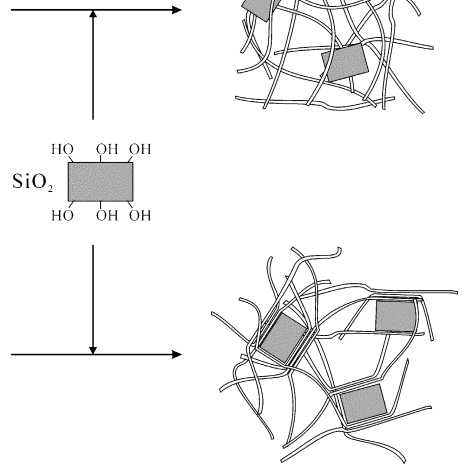

Fig. 7 Schematic mechanism for generation of the composites consisting of polymer and $\mathrm{SiO}_{2}$ nano-fillers. PS or MPS molecules are described as flexible tube shapes and $\mathrm{SiO}_{2}$ nanofiller shown as rectangular shapes with $\mathrm{OH}$ groups on the surface. The polymer molecules are attracted to the $\mathrm{SiO}_{2}$ nanofillers through the hydrogen bond or electrostatic interaction and further assembled on the $\mathrm{SiO}_{2}$ by their intermolecular hydrophobic forces. 
must be the key factor to make the PS polymer chains to assemble epitaxially and stack regularly on the surface of $\mathrm{SiO}_{2}$ nanofillers.

\subsection{Mechanical Properties of PS- and (PS+MPS)- Nanofiller Composites}

The mechanically hard and brittle properties of PS are sometimes disadvantageous in practical applications. Amorphous polymers molecules with high $T_{\mathrm{g}}$ such as PS cannot move freely at room temperature lower than $T_{\mathrm{g}}$ and it is easy to break down because of generation and propagation of microvoids in PS. ${ }^{17)}$

The mechanical properties of the present composites are summarized in Table II and Fig. 8. Interestingly, the mechanical properties of these composites demonstrate a uniform dependence on $P$ values independently of their compositions. The elongation $(\varepsilon)$ at the break point shows a tendency to simply increase with increasing $P$, whereas the yield strength $(\sigma)$ and the Young's modulus $(E)$ decrease linearly at the range of $P$ less than 0.497 and remain almost constant at larger $P$ values. It is worth remarking that the $\varepsilon$ value of $4.5 \%$ for (PS+MPS) $/ \mathrm{SiO}_{2}$ is enormously larger than those for PS or the others, in contrast to a slight decrease of its $\sigma$ and $E$ values relative to those for PS. The large elongation of the (PS+MPS) $/ \mathrm{SiO}_{2}$ composite is expected highly effective for improving the brittleness of PS. In this composite, the strong interaction between polymers and fillers would induce a significant decrease in intermolecular distances and an increase in regularity of intermolecular structures of PS, which serves to reduce the concentration of microvoids generated in the material leading to improvement of the mechanical property of PS.

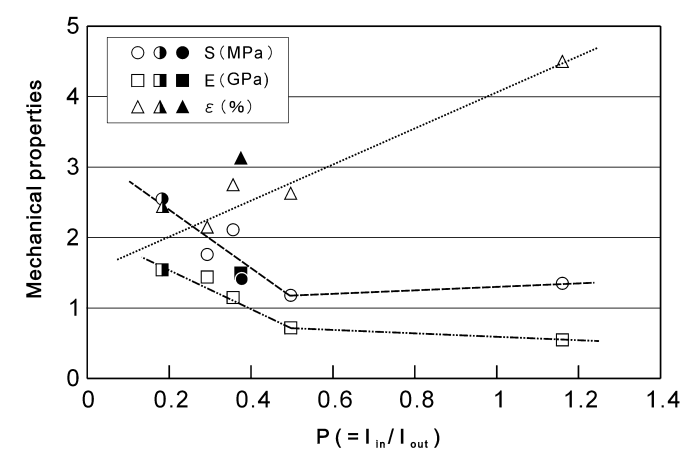

Fig. 8 Relationships between structural parameter $P\left(=I_{\text {in }} / I_{\text {out }}\right)$ and mechanical properties, yield strength $(S)$, initial modulous $(E)$ and elongation at break point $(\varepsilon)$. The solid and half-solid symbols are for the filler-free PS and MPS systems, respectively. The open symbols are for the other composite systems.

\section{CONCLUSIONS}

1) It is demonstrated that the structural properties of PS, PS+MPS, and their composites with $\mathrm{SiO}_{2}$ or $\mathrm{SiO}_{2}(\mathrm{St})$ can be well characterized in terms of X-ray parameters defined on the basis of two characteristic peaks observed in their WAXS patterns.

2) The strong interactions between $\mathrm{COO}$ - or $\mathrm{COOH}$ groups of polymer and $\mathrm{OH}$ groups on fillers make the polymer chains to be attracted and epitaxially assembled on the fillers in (PS+MPS)/SiO 2 composite, whereas the $\mathrm{PS} / \mathrm{SiO}_{2}$ composite without such strong interaction causes no significant change in intermolecular structure of polymer chains.

3) The ratio $(=P)$ of inner halo intensity $\left(I_{i n}\right)$ to outer halo intensity $\left(I_{\text {out }}\right)$ in WAXS is of great importance as a characteristic structural parameter which well characterizes the intermolecular structures of PS strongly dependent on the interaction between polymer and nanofillers.

4) It is found that the elongation, yield strength, and Young's modulus of PS and PS/nanofiller composites can be closely related to their $P$ values as a structural parameter.

5) The mechanical property analysis based on the $P$ parameter reveals that the composite of PS, MPS, and mesoporous $\mathrm{SiO}_{2}$ fillers is highly effective for improving the brittleness of PS mainly through the increase in elongation.

\section{REFERENCES}

1) Issues in Nanotechnology, Science, 290, 1523 (2000).

2) Antonnietti M, Goltner MC, Angew Chem Ind Ed Engl, 36, 910 (1997).

3) Gozin GA, Chem Commun, 419 (2000).

4) Usuki A, Kojima Y, Okada A, Kurauchi T, Fukushima Y, Kamigaito O, J Mater Res, 8, 1179 (1993).

5) Hasegawa N, Okamoto H, Kawasumi M, Usuki A, J Appl Poly Sci, 74, 3359 (1999).

6) Okada A, Usuki A, Mater Sci Engl, C3, 109 (1995).

7) Katz JR, Trans Faraday Soc, 32, 77 (1936).

8) Krimm S, Tobolsky AV, J Polymer Sci, 6, 667 (1951).

9) Krimm S, Tobolsky AV, Textile Res J, 21, 805 (1951).

10) Killian HG, Boueke K, J Polymer Sci, 58, 311 (1962).

11) Michell GR, AWindle AH, Polymer, 25, 906 (1984).

12) Kresge CT, Leonowicz ME, Roth WJ, Vartuli JC, Beck JS, Nature, 359, 710 (1992).

13) Fig. 21 in ref.11. 
14) Kobunsi Gakkai, “Kobunsi Bussei no Kiso”, p245-247 (1992), Kyoritu Syuppan.

15) Mark HF ed, "Encyclopedia of Polymer Science and Technology”, p224-226 (1970), John Willey \& Sons Inc, NY.
16) Usuki A, 02-3Polymer Frontier Preprint, 10 (2002).

17) Kobunsi Gakkai, "Kobunsi Bussei no Kiso”, p334-336 (1992), Kyoritu Syuppan. 